\title{
El AGRo EN URUguaY: RENTA DEL SUELO, INGRESO LABORAL Y GANANCIAS
}

\author{
Gabriel Oyhantçabal y Martín Sanguinetti ${ }^{1}$
}

Fecha de recepción: 07 de julio de 2016. Fecha de aceptación: 15 de noviembre de 2016.

\begin{abstract}
RESUMEN
Desde el año 2002, el sector agropecuario de Uruguay atravesó intensas transformaciones en un contexto de altos precios de los commodities y flujos de inversión extranjera. La presente investigación estudió una dimensión no abordada de estos cambios ligada a sus impactos en la distribución del ingreso, aportando a la literatura reciente en esta materia. En el periodo 2000-2015 se analizó la distribución del ingreso por fuente de remuneración (ingreso laboral, ganancia y renta del suelo), y por clase social incluyendo al Estado. Los resultados muestran que los terratenientes fueron el sujeto que más incrementó su apropiación de valor, creció levemente la masa salarial y no se modificó la participación estatal en el valor agropecuario ni en la renta del suelo.
\end{abstract}

Palabras clave: sector agropecuario, ingreso laboral, renta del suelo, plusvalor, Estado. Clasificación JEL: E25, J31, N56, O13, Q15.

\section{Agro in Uruguay: Ground Rent, Labor InCOME, AND Profit}

\begin{abstract}
Since 2002, the agriculture and livestock sector in Uruguay has undergone an intense transformation in the context of high commodities prices and rising foreign investment. This research studied an as-of-yet unaddressed dimension of these changes concerning their impact on income distribution to contribute to the recent literature on these matters. The distribution of income by source of remuneration (labor income, profit, and ground rent) and social class, including the State, in the period 2000-2015, was analyzed. The results show that landholders were the group whose appropriation of value increased the most. The total wage bill grew slightly, and state participation held steady in both the value of agriculture and livestock and ground rent.
\end{abstract}

Key Words: Agriculture and livestock sector, labor income, ground rent, surplus, State.

${ }^{1}$ Universidad de la República, Uruguay. Correos electrónicos: gaboyha@gmail.com y msanguin58@gmail.com, respectivamente. 


\section{L'AGRO EN URUGUAY: RENTE DU SOL, REVENUE DU TRAVAIL ET PROFITS Résumé}

Depuis l'année 2002, le secteur agricole de l'Uruguay a connu des transformations intenses dans un contexte de prix élevés des commodities et des flux d'investissement étranger. La présente enquête a étudié une dimension pas encore abordée de ces changements liés à leurs impacts sur la distribution des revenus, contribuant à la littérature récente sur ce sujet. Dans la période 2000-2015 on a analysé la distribution des revenus par source de rémunération (revenu du travail, profit et rente du sol), et par classe sociale, l'État y compris. Les résultats montrent que les propriétaires de terrain ont été ceux qui ont augmenté le plus leur appropriation de la valeur, que la masse salariale est légèrement accrue, et que la participation de l'État n'était pas modifiée en proportion de la valeur agricole ni dans la rente du sol.

Mots clés: secteur agricole, revenu du travail, rente du sol, plus-value, État.

\section{O AGRO NO URUGUAI: RENDA DA TERRA, REMUNERAÇÁO DO TRABALHO E LUCROS}

\section{Resumo}

Desde o ano de 2002, o setor agropecuário do Uruguai atravessou intensas transformaçóes num contexto de altos preços das commodities e fluxos de investimento estrangeiro. A presente pesquisa estudou uma dimensão não abordada destas mudanças unida a seus impactos na distribuição da renda, contribuindo à literatura recente nesta matéria. No período 2000-2015 se analisou a distribuição da renda por fonte de remuneração (remuneração do trabalho, lucro e renda do solo), e por classe social incluindo ao Estado. Os resultados mostram que os proprietários de terras foram o sujeito que mais incrementou sua apropriaçáo de valor, cresceu levemente a massa salarial e não se modificou a participação estatal no valor agropecuário nem na renda da terra.

Palavras-chave: : setor agropecuário, remuneraçáo do trabalho, renda da terra, mais-valia, Estado.

乌拉圭农业: 土地收益、劳动收入和利润 加夫列尔・奥义罕塔巴尔马丁・桑吉内蒂 摘要

自2002年起，在商品高价格和外资流入的背景下，乌拉圭农渔业经历了深 刻的变革。本文研究了在这些变革中此前没有触及到的方面, 即改革在收 入分配方面的影响, 以此来为该领域的研究做出贡献。本文分析了 20002015年期间报酬的分配（劳动收入、利润和土地收益）和各社会阶级（ 包括国家层面）的收入分配。结果表明地主提升了其私有价值、轻微增加 了大众工资而且并没有改变国家在农渔业和土地收益的价值。

关键词：农渔业部门劳动收入土地收益 增值国家 


\section{INTRODUCCIÓN}

Luego de una profunda recesión que afectó al país entre los años de 1999 y mediados de 2003 la economía de Uruguay inició un periodo de intensas transformaciones con altas tasas de crecimiento económico en un contexto dinamizado por determinantes internacionales como los altos precios de los productos de exportación y un creciente flujo de inversión extranjera directa (IED). ${ }^{2}$ Entre los ańos de 2004 y 2015 la tasa acumulativa de crecimiento del producto interno bruto (PIB) fue de $6.4 \%$ anual promedio, la tasa anual de formación bruta de capital fijo fue de $19.9 \%$ del PIB y las exportaciones de bienes y servicios crecieron 5.3\% por año (всU, 2016).

El sector agropecuario fue uno de los más dinámicos, no sólo por su propio crecimiento, sino por su efecto multiplicador en el conjunto de la economía y por ser el sector más dinámico en materia exportadora. Luego de caer la producción agropecuaria en volumen físico entre los años de 1998 y 2001, de 2002 a 2015 el PBI agropecuario creció un $42.5 \%$ en pesos constantes de 2005 , a una tasa anual de $3.3 \%$, aunque por debajo del crecimiento del resto de la economía, que en el mismo lapso creció a razón de $6.2 \%$ por año (BCU, 2016).

Una de las particularidades del crecimiento del sector en el periodo fue la variación en la composición sectorial de su PIB consecuencia de la expansión de nuevos rubros como la forestación y la soja, que en 2011 ocuparon 2617 millones de hectáreas, $16 \%$ de las 16.36 millones de hectáreas agropecuarias (DIEA, 2014). La forestación comenzó su expansión en la década de los noventa pasando de 186 mil hectáreas en 1990 a 660 mil hectáreas en el año 2000 y 1.071 .128 hectáreas en el año 2011. Por su parte la expansión agrícola data de comienzos de 2000, fundamentalmente por el avance del cultivo de soja, pasando de un área ocupada de 404.291 hectáreas en el año 2000 a 1.545.889 hectáreas para el año 2011 (DIEA, 2003 y 2014). Si se considera el área sembrada por ejercicio agrícola, lo que incluye los sistemas de doble cultivo anual, se observa un incremento de 637.810 hectáreas en el año 2000 a 1.947.113 hectáreas en el año 2011 (DIEA, 2003 y 2014). Entre los cultivos agrícolas la soja dio un salto exponencial en el área sembrada pasando en 2013. Del total invertido en ese rango de años, 19.853 millones de dólares, $61.4 \%$ correspondió a aportes de capital (BCU, 2016). En el periodo 1983-2004 el peso de la IED en el PIB fue de un $0.8 \%$, mientras que en el periodo 2005-2014 ascendió a casi el 6\%, cifra que prácticamente duplica el promedio para América Latina en igual periodo (Cepal, 2015). 
de 8.900 hectáreas en la zafra 1999/2000 a 1.334.000 hectáreas en la zafra 2014/2015 (DIEA, 2015).

Para un país que prácticamente ocupó la totalidad de su frontera agropecuaria a fines del siglo XIX, la expansión de la forestación y la agricultura supuso el desplazamiento territorial de otras actividades agropecuarias. De las comparaciones intercensales 1990-2000-2011 de uso del suelo, surge que el área de campo natural (pastizales naturales) se redujo en 2.132.000 hectáreas en 21 años, mientras que entre los años de 2000 y 2011 disminuyó en 262 mil hectáreas el área de praderas artificiales. En ambos casos se trata de usos del suelo destinados principalmente a la ganadería de carne y lana en el primer caso, y la ganadería de carne y leche en el segundo.

Estas transformaciones en el uso del suelo se expresaron en un intenso dinamismo en el mercado de tierras. En el periodo 2000-2015 se comercializaron 7.84 millones de hectáreas que representan el $48.1 \%$ del territorio nacional, el precio de compraventa de la tierra pasó de 448 a 3.594 dólares/ hectárea con un pico de 3.934 dólares/hectárea en el año de 2014, y el precio de arrendamiento anual pasó de 28 a 124 dólares/hectárea con un pico de 174 dólares/hectárea en 2014 (DIEA, 2016a y 2016b).

Sin embargo, y a pesar de su magnitud, no se ha estudiado el impacto de estas transformaciones en la distribución del ingreso. Entre los organismos oficiales, el Banco Central del Uruguay (BCU), encargado de Sistemas de Cuentas Nacionales (sCN), dejó de estimar la cuenta de generación de ingresos en el año de 2005; la Encuesta Anual de Actividad Económica del Instituto Nacional de Estadística (INE) no incluye en su muestra las explotaciones agropecuarias; y el organismo encargado de la estadística agropecuaria, la Dirección de Estadísticas Agropecuarias (DIEA-MGAP), no aborda la distribución del ingreso sectorial.

Tampoco existen estimaciones rigurosas sobre la magnitud del plusvalor apropiado como renta del suelo, aspecto relevante a la hora de analizar la dinámica de un sector que basa su actividad en la explotación de este recurso, un medio de producción natural, finito, heterogéneo y monopolizable que impone leyes específicas al desarrollo del capitalismo, en tanto la formación de los precios de producción y de mercado deben permitir la apropiación de renta diferencial y absoluta o de simple monopolio (Foladori, 2013).

La literatura nacional reciente que aborda tópicos en torno a la distribución del ingreso en Uruguay es de carácter fundamentalmente académico. Esta literatura inicialmente centrada en el estudio de la distribución personal del ingreso (distribución por decil o a través del índice de Gini), pasó a considerar el vínculo entre la distribución personal y la distribución funcional del 
ingreso, en general desde la perspectiva de la remuneración por factor de producción (Burdin et al., 2014; Burdin et al., 2015; De Rosa y Vigorito, 2015).

Entre los antecedentes a destacar, el Programa de las Naciones Unidas para el Desarrollo (PNUD, 2008: cap. 3) a partir de las cuentas nacionales estimó la distribución funcional del ingreso para el global de la economía. El estudio permite considerar en el largo plazo la participación del salario en el valor apropiado nacionalmente, evidenciando como grandes tendencias el intenso proceso de desvalorización de la fuerza de trabajo asociado a la última dictadura militar (1973-1985) que redujo la participación del salario en el PIB de 40 a $28 \%$, una leve reducción posdictadura que volvió a desplomarse con la crisis de 1999-2002.

Trabajando con las mismas series, Alarco (2014) estimó la participación de la masa salarial para 15 países de América Latina considerando solo el salario desde 1950 hasta 2010. En el caso de Uruguay la serie va de 1955 a 2011. Al igual que en el estudio anterior, en Uruguay se registra una caída abrupta de la masa salarial hasta el año de 1984, con una recuperación en los noventa, una nueva caída con la crisis 1999-2002, y luego una magra recuperación alcanzando cifras cercanas al 36\% del PIB en el 2011.

Por su parte, Abeles et al. (2014) también con una mirada de largo plazo y comparativa para todos los países de América Latina, estiman la participación del ingreso laboral en el producto en tres momentos: 1990, 2000 y 2009. Su diferencia con el trabajo antes citado, es que incorporan al análisis la parte del ingreso mixto que corresponde a salarios y la que corresponde al capital. Para Uruguay las estimaciones son sólo para los años 2000 y 2010, registrando que la participación de la masa salarial cayó de 47.4 a 45.8\%.

Con una perspectiva teórica anclada en la economía política, Notaro (2012) estima la participación en el Ingreso Nacional Bruto Disponible (INBD) de los ingresos de los sectores populares (obreros y empleados, cuenta-propistas, pasividades y transferencias), de 2006 a 2010 obteniendo que el mismo oscila en torno al $41 \%$ del INBD.

Los trabajos del Instituto Cuesta Duarte (ICD, 2011) y de Burdín et al. (2014) son las dos investigaciones que han estimado la participación de la masa salarial en el рів desde 2005 trabajando con base en los microdatos de la Encuesta Continua de Hogares (ЕСH). La diferencia entre ambos trabajos es que Burdín et al. (2014) utilizan datos administrativos de la Dirección General de Impositiva (DGI) para mejorar los problemas de subestimación del ingreso del capital y datos administrativos del Banco de Previsión Social (вPS) para lograr una mejor estimación del salario. En cuanto al nivel, el ICD estima que la masa salarial creció de 26 a 30\%, entre 2005 y 2010; mientras que Bur- 
dín et al. (2014) estiman un crecimiento de 28 a 38\% en los mismos años, lo que puede deberse a la diferencia metodológica antes planteada.

Por último, De Rosa y Vigorito (2015) estiman la distribución funcional del ingreso trabajando con registros tributarios de las empresas que pagan Impuesto a la Renta de las Actividades Empresariales (IRAE), que no abarca a la totalidad de las empresas, siendo el único antecedente relevado que contiene una estimación de distribución del ingreso para el sector agropecuario. En promedio obtienen que los salarios representan el $47.6 \%$ del ingreso apropiado en 2012, aunque con importantes diferencias entre ramas: las primarias destinan 32-33\%, mientras que las industriales más de 50\%.

Esta investigación se propone avanzar en el estudio de la distribución del valor apropiado por el sector agropecuario de Uruguay en el periodo 20002015, en el entendido de que estudiar la desagregación del valor, y en particular la renta del suelo, es relevante tanto para entender los efectos distributivos del reciente boom agropecuario como para aportar insumos para el diseño de políticas redistributivas.

El análisis se realizó en dos niveles diferentes. Uno más abstracto que aborda la distribución primaria en las tres formas rediticias en que, en función de las relaciones de producción, se distribuye el nuevo valor entre los poseedores de las diferentes fuerzas o factores que participan de la producción: el ingreso laboral que remunera la fuerza de trabajo, la ganancia que remunera al capital y la renta del suelo que remunera a sus propietarios, siendo estas últimas las formas que adopta el plustrabajo o plusvalor en la sociedad capitalista (Marx, 1980). Y otro nivel más concreto que aborda la distribución secundaria del mismo valor entre las clases sociales que participan del proceso económico (capitalistas, terratenientes, asalariados, productores mercantiles directos) ${ }^{3} \mathrm{y}$ el Estado que apropia plusvalor para reproducir las condiciones generales de acumulación. ción y utilizan fuerza de trabajo familiar. Anteriormente conceptuados como "pequeńos productores" o "campesinos", en la actualidad parte de la academia y de los gestores de políticas públicas los define como "agricultores familiares". Son asimilables a lo que en las cuentas nacionales se define como cuenta propia con local, y cuyo ingreso es mixto. 


\section{METODOLOGÍA}

La fuente principal para estimar la proporción de valor apropiado por sector de actividad son las cuentas nacionales publicadas regularmente por el BCU. En este trabajo se analizó la distribución relativa del valor apropiado nacionalmente por un sector de actividad, el valor agregado bruto (VAB), con las cifras agregadas del SCN en dólares americanos corrientes, considerando que expresa de buena forma la producción anual valorizada excluyendo las fluctuaciones de la moneda nacional (peso uruguayo). La conversión de pesos uruguayos a dólares americanos se realizó utilizando el tipo de cambio nominal promedio anual.

El valor total apropiado por el sector agropecuario se encuentra discriminado en el sCN siguiendo la Clasificación Industrial Internacional Uniforme (CIIU) revisión 3 dentro de las actividades primarias bajo la denominación "agro" (rama A), subdividida en tres sectores de actividad: "Cultivos en general; servicios agrícolas aplicados a estos cultivos" (rama A.011), "Cría de animales; servicios ganaderos" (rama A.012) y "Silvicultura, extracción de madera y actividades de servicios conexas” (rama A.020).

\section{Distribución por fuentes de ingreso}

En un nivel más abstracto se abordó la distribución del valor entre el ingreso laboral que remunera la fuerza de trabajo y la plusvalía entendida como el valor excedente que produce el consumo de la fuerza de trabajo, y que remunera al capital bajo la forma de la ganancia media y a los terratenientes bajo la forma de renta del suelo. Se trata de lo que la literatura contemporánea conceptualiza como distribución funcional del ingreso, y que en su momento Marx (1980) definiera como las fuentes de ingreso de las "tres grandes clases de la sociedad moderna”.

En tanto el SCN produce información bruta, sin contabilizar el consumo de capital fijo, la renta y ganancia son brutas. De todas formas, si se toman como referencia las estimaciones recientes para la industria manufacturera en Uruguay, se tiene que la tasa de depreciación fue del entorno del $4 \%$ del vaB entre los ańos de 2009 y 2012 en el caso de Olmos (2015) que trabaja con base en registros tributarios, mientras que la Encuesta Anual de Actividad Económica registra que de 2003 a 2010 la depreciación fue de $8.5 \%$ promedio (INE, 2016). 
La renta del suelo agraria se calculó asumiendo que todos los dueños del suelo con actividad agropecuaria comercial, que acumulaban 16.36 millones de hectáreas en 2011, perciben renta, sean simultáneamente empresarios y dueños del suelo (en cuyo caso reciben la renta a través del precio de las mercancías), o sean solo propietarios que arriendan su tierra a cambio de renta, quedando ésta separada de la ganancia. La renta se estimó a través de las series de precio de arrendamiento publicadas por la DIEA, asumiendo que el precio de arrendamiento equivale directamente a la renta o, lo que es la mismo, que a través del precio de arrendamiento los terratenientes no están apropiando ni parte de la ganancia de los capitalistas ni parte del valor de la fuerza de trabajo resultado de su pago por debajo de su valor. El componente que sí integra el precio de arrendamiento junto a la renta es la depreciación del capital fijado al suelo (instalaciones, fertilidad, etcétera) que por falta de información no se pudo deducir, pero que suponiendo una vida útil de las instalaciones agropecuarias de entre 40 y 50 años oscilaría entre 2.5 y $2 \%$ del vaB.

Como se mencionó, la renta del suelo es apropiada a través de dos formas principales: 1) como precio de arrendamiento para aquellos que arriendan sus campos a explotaciones agropecuarias, 2) como parte de la ganancia en el caso de los productores que a su vez son dueños de sus campos. Es importante señalar que la renta calculada no es toda la renta del suelo que apropia el Uruguay como espacio nacional en la acumulación mundial de capital, sino sólo la apropiada por terratenientes. La renta de la tierra puede ser (y de hecho es) derivada primariamente hacia otros actores sociales, es decir, sin llegar a manos de los terratenientes, producto de la intervención del Estado mediante sobrevaluación del tipo de cambio, impuestos a las exportaciones agropecuarias, fijación de precios de las mercancías agrarias y otros mecanismos (Ińigo Carrera, 2007).

Para el cálculo de la renta del suelo por hectárea se partió de los datos de precio de arrendamiento que publica desde 2007 la DIEA a partir del procesamiento de los datos de arrendamientos registrados en la Dirección General de Registros del Ministerio de Educación y Cultura, lo que prácticamente representa el $100 \%$ de los contratos de arrendamiento formal. Las cifras publicadas establecen el precio de arrendamiento a nivel nacional, así como discriminan los precios por destino productivo. A partir de este desglose por rubro se reconstruyó la renta del suelo ponderada para la totalidad de la superficie productiva a partir de las cifras de uso del suelo con base en los Censos Generales Agropecuarios (DIEA), las encuestas por rubro de la DIEA y las declaraciones juradas a Dirección y Control de Semovientes (DICOSE). Este ajuste es importante ya que el promedio nacional esconde el problema de que las magnitudes 
de superficie arrendadas anualmente por rubro no equivalen al uso del suelo en la totalidad de la superficie productiva, en tanto hay rubros como la agricultura donde alrededor del $70 \%$ de la superficie está bajo arrendamiento, mientras que en la ganadería el porcentaje baja a un 30\%. En el anexo 1 se presenta el detalle de superficie ocupada, precio de arrendamiento, renta total y porcentaje arrendado según uso del suelo.

Con este procedimiento se calculó una renta del suelo ponderada que, según el año, está entre 55 y $82 \%$ del precio de arrendamiento promedio nacional. Con el ponderador del año 2007 (76\%) se ajustó la renta para el periodo 2000-2006 en los cuales sólo existen promedios nacionales sin discriminar actividad productiva. Finalmente, la magnitud anual de la renta se calculó multiplicando la renta por hectárea promedio anual por el total de la superficie productiva nacional obtenida de los censos agropecuarios (2000 y 2011), asumiendo que la superficie productiva en los años sin censo evolucionó a una tasa constante con respecto a la tasa 2000-2011.

El ingreso laboral se estimó agregando la remuneración de los asalariados, de los patrones cuando éstos declaran ingresos por el consumo de su fuerza de trabajo y de los productores mercantiles directos, cuya remuneración es computada en las cuentas nacionales como "ingreso mixto". De 2000 a 2005 las cuentas nacionales (BCU, 2016) ofrecen información de la masa salarial y del ingreso mixto que en el caso de esta fuente agrega el ingreso de los productores mercantiles con el salario patronal. De 2006 a 2015 a partir de los microdatos de la ECH se obtuvo la masa salarial líquida de asalariados, la remuneración de los patrones y el ingreso mixto. En el año 2010 como la ECH sobrestima la población del sector en general, pero en particular la cantidad de asalariados en las tres ramas, se ajustó la masa de ingresos según se muestra en el anexo 2.

Para construir la masa salarial nominal de asalariados, se agregaron los aportes personales y patronales a la seguridad social a partir de los datos administrativos del BPs y los aportes al seguro estatal de salud (FONASA), y en el caso del ingreso laboral patronal se agregaron sus aportes personales al BPs.

Tanto en el caso de los asalariados, como en el de cuentapropistas y patrones, no se imputaron al ingreso laboral los tributos correspondientes al Impuesto a la Renta de las Personas Físicas (IRPF) categoría 2 que pagan los ingresos por encima de las ocho Bases de Prestaciones y Contribuciones (BPC, equivalente a un ingreso nominal mensual de 790 dólares en 2015), ya que sólo están disponibles de 2009 a 2011. De todas formas, procesando los datos de la DGI, se obtiene que para esos tres años el IRPF categoría 2 representó el $0.35 \%$ del $\mathrm{VAB}$ agropecuario. 
En el caso del ingreso de los productores mercantiles directos, teóricamente estos condensan en una misma figura varias personificaciones económicas o formas del valor (salario, renta y ganancia). Sin embargo, se consideró que el ingreso mixto que computa el SCN incluye fundamentalmente la remuneración de su fuerza de trabajo y la renta de la tierra que apropian aquellos que también son propietarios del suelo. Existe la posibilidad de que ese cómputo incluya ganancias, pero en la medida que la mayoría de estos productores utilizan solo fuerza de trabajo familiar y están en condiciones de reproducción simple, se partió del supuesto de que no apropian plusvalía bajo la forma de ganancia. Por este motivo, para obtener el ingreso laboral de los productores mercantiles, se restó al ingreso mixto calculado la masa de renta que apropian aquellos que son propietarios, la que se obtuvo considerando el porcentaje de la superficie que estos productores tienen bajo propiedad, la que surge del procesamiento de los censos agropecuarios de 2000 y 2011 realizado por Tommasino et al. (2014).

Finalmente, la ganancia se calculó sustrayéndole al VAB total la renta y el ingreso laboral.

\section{Distribución social del ingreso}

En este nivel de abstracción se abordó la distribución del valor entre las clases sociales que participan del proceso económico incluyendo la apropiación estatal del valor sectorial, en lo que Notaro (2012) conceptualiza como distribución social del ingreso. En este nivel se superponen en una misma figura varias personificaciones económicas. Así, los capitalistas apropian ganancias (por definición), pero también renta cuando son dueños de la tierra, y salario cuando trabajan (ingreso laboral patronal); los terratenientes sólo apropian renta del suelo; los productores mercantiles directos apropian salario como trabajadores, renta cuando son dueños de la tierra y eventualmente ganancia si ingresan en un proceso de acumulación ampliada; y los asalariados sólo perciben salario por la venta de su fuerza de trabajo. Por su parte, el Estado se apropia de una parte del plusvalor vía tributos que afectan tanto a las ganancias como a la renta, y vía renta del suelo directamente como terrateniente a través del Instituto Nacional de Colonización (INC), un ente público que controla cerca del $2 \%$ de la superficie productiva, y que arrienda parcelas de tierra a productores mercantiles a precios subsidiados.

El valor apropiado por los terratenientes resulta de la renta que estos se apropian por la propiedad del suelo menos los impuestos a la tierra que afectan su propiedad. La renta se obtuvo ponderando la renta del suelo total para 
el Uruguay en función del porcentaje de tierra bajo arrendamiento según uso del suelo, como se observa en el anexo 1, y los impuestos a la propiedad del suelo del procesamiento de la recaudación tributaria del Estado ponderados en función de la fracción de renta que apropian. Cabe aclarar que este método podría estar sobre-estimando la renta apropiada por terratenientes en tanto existen contratos de arrendamiento de más de un año que no siguen la evolución de la renta y se actualizan recién cuando se renueva el contrato.

El ingreso del Estado se calculó agregando la recaudación tributaria que afecta al sector agropecuario y la recaudación que obtiene el INC por el arrendamiento de sus explotaciones (véanse detalles en anexo 3). La recaudación tributaria para el periodo 2000-2015 se obtuvo de los datos publicados por la DGI (2016) y de los informes que en base a DGI y estimaciones propias publica anualmente la Oficina de Planeamiento y Política Agropecuaria (OPYPA) dependiente del MGAP (Tambler, 2000, 2005, 2009 y 2015). Se trata de tributos que gravan la renta del suelo y abonan sólo los propietarios, y tributos que gravan la producción (incluyendo ganancias) y abonan sólo los titulares de las explotaciones agropecuarias. Los ingresos del INC se obtuvieron del procesamiento de sus balances contables (ítem "explotación de inmuebles"). Se asumió que en 2005 se arrendaban 250 mil hectáreas, y que en el periodo 2005-2015 se adquirieron 10 mil hectáreas más por año, siendo que el precio de arrendamiento promedio del INC equivale aproximadamente a un 35\% de la renta ponderada. Asimismo, con estas cifras se calculó la presión tributaria, o la apropiación estatal de valor relativa, como tributos totales sobre vaB agropecuario y la presión estatal sobre la renta del suelo como renta apropiada (vía tributos y INC) sobre renta total.

El cálculo del valor apropiado por los asalariados y los productores mercantiles directos se presentó en el apartado anterior al abordar el ingreso laboral como un todo, y surge del SCN (2000-2005) y del procesamiento de la ECH y de registros de aportes a la seguridad social (2006-2015). Finalmente, el ingreso de los capitalistas se calculó sustrayéndole al VAB total la remuneración de los otros sujetos. 


\section{DISTRIBUCIÓN DEL VALOR AGROPECUARIO}

\section{Distribución por fuente de remuneración: ingreso laboral, renta y ganancias}

La gráfica 1 resume la distribución del VAB agropecuario en el periodo 20002015 expresado en miles de millones de dólares. Se observa una tendencia general de crecimiento del VAB a partir del año 2002 asociada a las transformaciones antes mencionadas y que está relacionado a la superación de la crisis económica 1999-2002 y al contexto extraordinario de incremento en los precios de los productos exportados desde Uruguay. Los únicos años donde se registran caídas relevantes en el producto son en 2009, ligada a la crisis internacional que comenzó en 2008 y a los efectos del severo déficit hídrico ("sequía") de 2008, y en 2014 y 2015 relacionado con el inicio del ciclo descendente en el precio internacionales de los commodities.

La evolución de la distribución entre ingreso laboral y plusvalor (renta más ganancias) muestra dos momentos diferenciados. De 2000 a 2004 el plusvalor crece en términos relativos y absolutos, al tiempo que el ingreso laboral sigue el proceso inverso. El primero pasa de 61 a $80.5 \%$ del VAB y en términos absolutos crece de 790 a 1.182 millones de dólares, mientras que el ingreso laboral cae de 39 a 20\% del VAB y se reduce de 506 a 287 millones de dólares.

Gráfica 1. Distribución del vaB agropecuario en ingreso laboral, ganancias y renta del suelo 2000-2015 en miles de USD

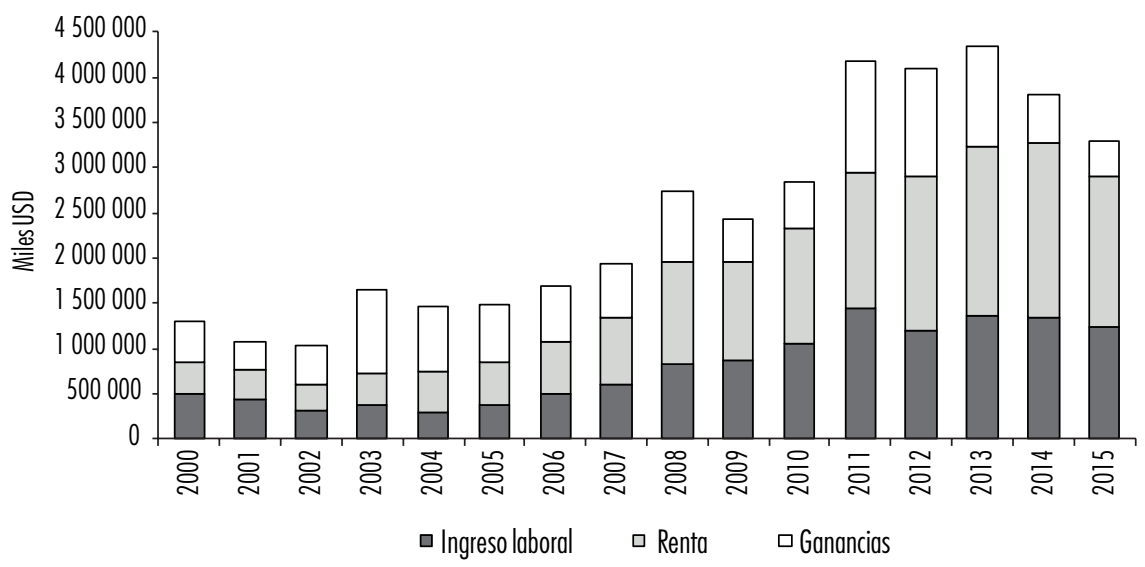

Fuente: elaboración propia. 
Por el contrario, en el periodo 2005-2015 se recupera en términos absolutos y relativos el ingreso laboral, mientras cae en términos relativos el plusvalor pero se incrementa significativamente en cifras absolutas. El ingreso laboral se recupera en el periodo pasando de $20 \%$ a un máximo de $38 \%$ del VAB en 2015 , mientras que en cifras absolutas crece de 381 a 1.250 millones de dólares. Por su parte, el plusvalor cae en términos relativos, oscilando entre 73\% (2005) y $62 \%$ del VAB (2015), pero crece en términos absolutos de 1.093 a 2.040 millones de dólares, con un pico máximo de 2.965 millones de dólares en 2013.

Si se analiza la distribución del plusvalor entre ganancias y renta se observa que del 2000 al 2003 crecen las ganancias en un contexto de retracción del ingreso laboral y relativa estabilidad de la renta, mientras que desde 2004 ante el escenario de expansión sectorial de la mano del boom de los commodities se produce un incremento absoluto y relativo de la renta de la tierra que pasa del $21.7 \%$ del VAB agropecuario y 361 millones de dólares en 2003 a 50.4\% del VAB y 1.658 millones de dólares en 2015. Por el contrario en ese periodo (2003-2015) las ganancias reducen su participación en el vAB oscilando entre 20 y $30 \%$ y llegando a un piso de $11.6 \%$ en 2015 , mientras que en cifras absolutas siguen un curso oscilante con mínimos de 486 y 383 millones de dólares en 2009 y 2015, y máximos de 1.222 y 1.119 millones de dólares en 2011 y 2012.

Del análisis conjunto de las tres fuentes de remuneración surgen varias conclusiones. En primer lugar, queda claro que el periodo de crisis económica (2000-2003) presionó para la desvalorización de la fuerza de trabajo, expresado en la reducción de la masa de ingreso laboral, como forma de recuperar la rentabilidad del capital, lo que se expresa en la expansión significativa de las ganancias en el VAB, al tiempo que la renta se mantiene relativamente estable. En otros términos, la crisis se resuelve inicialmente desvalorizando la fuerza de trabajo, antes que afectando la masa de renta.

En segundo lugar, desde 2003 se inicia una etapa fuertemente expansiva en el valor apropiado por el sector que modifica la participación relativa de las fuentes de remuneración. El boom de los commodities permite expandir la participación relativa del ingreso laboral que se expresa en un significativo incremento del valor de la fuerza de trabajo en la medida que la masa de ingreso laboral creció por la expansión en los ingresos reales de los asalariados entre 2006 y 2015 más que por la cantidad de ocupados que tiende a mantenerse estable (véase gráfica 2). En el caso de las otras clases (cuenta propia y patrones), es destacable que, como tendencia, se mantiene el número de ocupados al igual que los asalariados, pero a diferencia de éstos su ingreso real no registra incrementos significativos, en tanto entre los años de 2006 y 2015 el salario 
Gráfica 2. Número trabajadores (eje izquierdo) y salario real anual (eje derecho) por sujeto social de 2006 a 2015

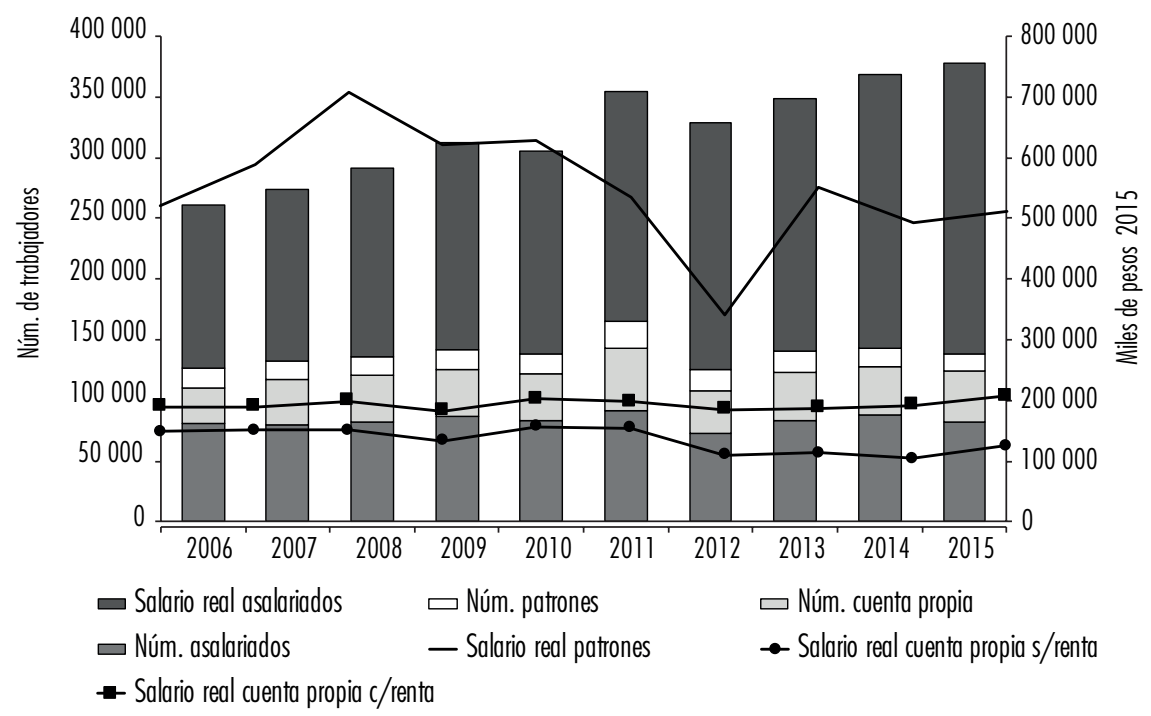

Fuente: elaboración propia.

patronal real cae un $1.7 \%$ mientras que en el caso de los cuenta propia sube un $9.6 \%$, pero si se quita la renta, su remuneración real cae un $16.1 \%$, siendo la clase que registra menores ingresos lo que podría estar explicando su proceso de proletarización, en tanto entre los años 2000 y 2011 los establecimientos de tipo familiar (con la definición oficial) se redujeron de 32.696 a 25.580 (Tommasino et al., 2014).

Sin embargo, la expansión relativa y absoluta del ingreso laboral no afectó la masa de plusvalor, sino por el contrario coincidió con su expansión absoluta bajo la forma de renta y ganancias. Esto es expresión de una fase virtuosa en el proceso de valorización de capital directamente ligada a los precios internacionales extraordinarios que permitieron la expansión de todas las fuentes de remuneración. En el caso particular de los salarios, hay que destacar que desde 2005 se inició una nueva etapa en materia de regulación del conflicto capitaltrabajo en el sector agropecuario con la llegada al gobierno del Frente Amplio. Entre las principales medidas impulsadas que permitieron elevar el ingreso real de los asalariados un $76.1 \%$ destacan las siguientes: la convocatoria por primera vez en la historia nacional a los Consejo de Salarios para el sector 
agropecuario (rural), la aprobación de la ley que regula la jornada laboral en ocho horas y la regularización de las tercerizaciones (Carámbula et al., 2012).

En el caso de la renta del suelo, su crecimiento extraordinario es producto de la expansión de rubros agropecuarios altamente dinámicos como la soja y la forestación en un contexto de altos precios internacionales y alta rentabilidad de estos cultivos, a lo que se sumó un flujo creciente de capital a la tierra como medio de atesoramiento y valorización vía renta del suelo en un contexto mundial de crisis financiera. De 2003 a 2015 el вCU (2016) registra un flujo de IED en tierras de 1.962 millones de dólares, 8.7\% de la IED total hacia Uruguay en ese periodo, cifra equivalente a 1,53 millones de hectáreas a precios promedio de cada año.

Las ganancias siguen un curso oscilante, resultado de que salarios y renta tienden a fijarse previo a los ciclos productivos y sólo luego se ajustan (al alza o a la baja) en función de la rentabilidad obtenida por el capital. Viéndolo de otra forma, la renta y el ingreso laboral pudieron crecer de 2004 en adelante dado el incremento de la rentabilidad del capital agrario, al tiempo que el importante descenso en el precio de los commodities registrado desde 2014 ya se expresó en un descenso de $14 \%$ en la renta total en 2015 y es esperable que se traduzca en un ajuste salarial.

\section{Distribución social del ingreso}

Cuando el foco se pone en la distribución social del vaB agropecuario entre las clases sociales que participan del proceso productivo y el Estado que apropia plusvalor para reproducir las condiciones generales de acumulación se observan tendencias congruentes con las analizadas en el apartado anterior (véase gráfica 3). En los años de crisis (2000-2003) se reduce la participación de los asalariados en el producto de 31 a 17\%, se mantiene la participación relativa del Estado y los terratenientes (en el entorno de 8-9\% del VAB), y crece de forma significativa la participación de los capitalistas en el producto de 43 a $64 \%$, lo que expresa el proceso de reestablecimiento de las condiciones de la acumulación a expensas del valor de la fuerza de trabajo. De 2004 a 2013 se registra un significativo incremento del vaB total que se tradujo en un incremento absoluto del valor apropiado por todos los sujetos, y que en términos relativos muestra como principal transformación un avance de los terratenientes a costa de los capitalistas en tanto los primeros pasan de apropiar 8 a 16\% del vaB, mientras que los segundos reducen su participación de 61 a 50\%. En esos años la participación del Estado se mantiene en el entorno del 7\%, la de los asalariados oscila entre 15 y $18 \%$ y la de los productores mercantiles oscila 
Gráfica 3. Distribución del VAB agropecuario en miles de USD de 2000 a 2015 por sujeto social

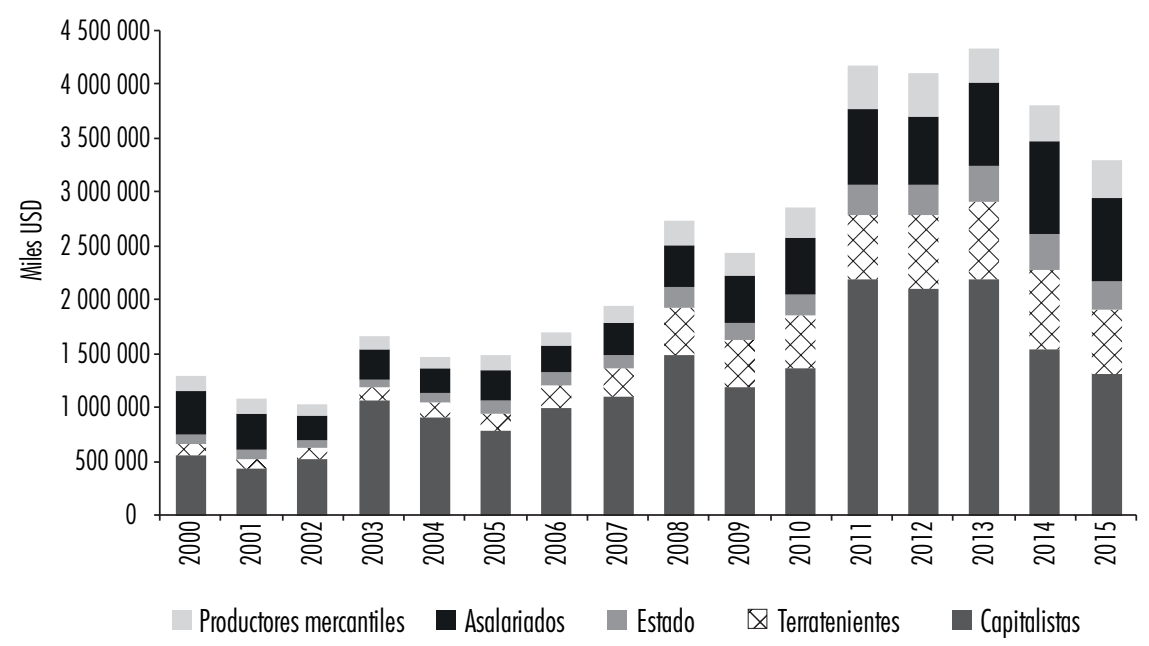

Fuente: elaboración propia.

entre 7 y 10\%. Finalmente, 2014 y 2015 muestran el agotamiento del ciclo expansivo de los commodities afectando la participación en el producto de los capitalistas a costa del crecimiento de la participación de los asalariados que llegan a 24\% del VAB en 2015 .

De esta forma los 16 años bajo estudio dan cuenta primero (2000-2003) de un proceso de re-establecimiento de las condiciones de acumulación que permite a los capitalistas incrementar su participación en el producto para elevar su tasa de ganancia, luego (2004-2013) un periodo expansivo que en un contexto de altos precios de las mercancías agrarias y flujos de IED hacia la tierra posibilitan a los dueños de la tierra incrementar su participación en el producto a costa de los ingresos de los capitalistas en tanto los otros sujetos no ven afectada su participación en el producto y, finalmente (2014 y 2015), el inicio de un periodo de estancamiento/recesión que afecta significativamente los ingresos de los capitalistas, empieza a afectar los ingresos de los terratenientes que reducen su participación absoluta pero no relativa en el producto y permite una expansión relativa de los ingresos de los asalariados en el producto. De seguir la reproducción del capital sus tendencias seculares lo esperable es que la recuperación de la rentabilidad se procese ajustando rentas y salarios, lo que ya se ha expresado en las pautas para 2015 y 2016 del Poder Ejecutivo de cara a los Consejos de Salarios. 
Gráfica 4. Distribución de la renta de la tierra en miles de USD por sujeto social de 2000 a 2015

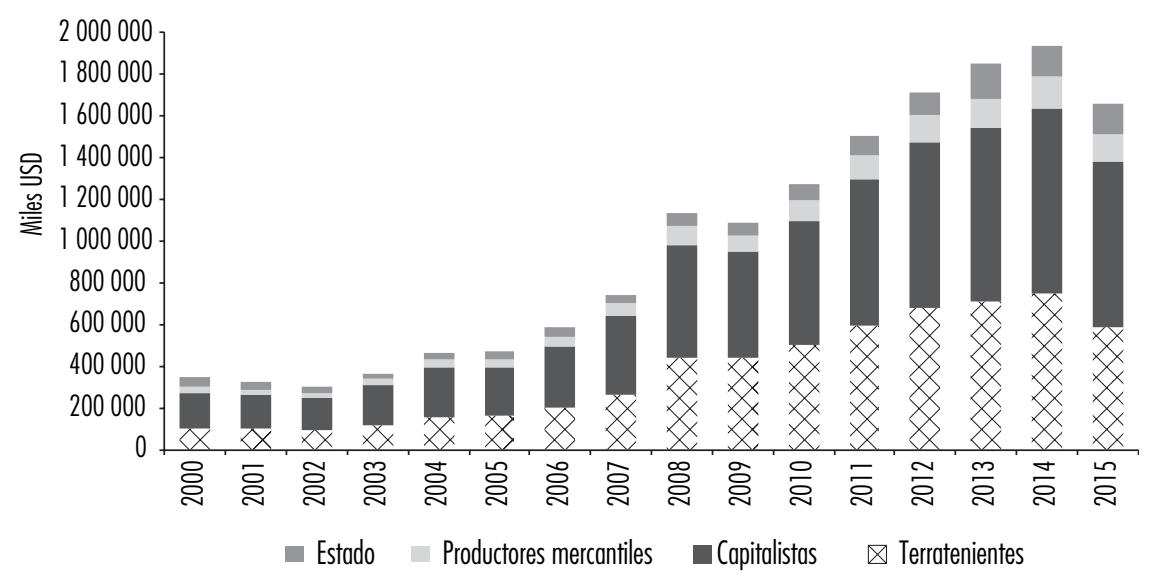

Fuente: elaboración propia.

Dos aspectos de este proceso merecen particular atención. En primer lugar la distribución de la renta de la tierra entre el conjunto de los sujetos que se disputan la apropiación del VAB agropecuario, y en segundo lugar las formas a través de las cuales el Estado apropia plusvalor agropecuario. Los propietarios de la tierra apropian renta del suelo a través del precio de arrendamiento para aquellos que arriendan sus campos (terratenientes) y como parte de la ganancia en el caso de los productores que a su vez son dueños de la tierra (capitalistas). En este nivel de análisis se discriminó la apropiación de la renta por sujeto. Entre los años 2000 y 2015 la renta del suelo pasó de 349 a 1.658 millones de dólares con un pico de 1.939 millones en 2014. Su distribución (véase gráfica 4) evidencia que creció la participación de los terratenientes de 29 a $35.6 \%$ con un máximo de $40.2 \%$ en 2009 , la participación de los capitalistas osciló entre 45 y $50 \%$ y la de los productores mercantiles en el entorno del 8\%, y la participación del Estado primero cayó de 14.4 a 5\% de 2000 a 2009, para luego subir a $8.6 \%$ en 2015 . Las cifras evidencian que la distribución de la renta sigue una tendencia fuertemente estable, siendo la principal "variable de ajuste" la proporción de renta que apropia el Estado en función de los cambios en la política tributaria.

La participación del Estado en el VAB agropecuario y en la renta del suelo muestra el mismo patrón. En los años de crisis (2000-2003) cae la participación del Estado en el vab de 8 a 4\% y de 14.4 a 5\% en la renta del suelo, 
producto de un conjunto de políticas que "aliviaron" la presión fiscal ${ }^{4}$ sobre el sector para acelerar la recuperación de la tasa de ganancia del capital. Por el contrario, de 2004 en adelante el crecimiento económico va acompañado de una serie políticas que incrementan la presión fiscal y la apropiación estatal de renta. En el primer caso las modificaciones introducidas permiten recuperar el nivel de presión tributaria pre-crisis en el entorno del 7-8\%, obteniendo una presión efectiva que no difiere con otros sectores de la economía (Olmos, 2015). En el segundo caso, la apropiación estatal de renta se estabiliza en el entorno del $8 \%$, en un periodo en el cual se aprobaron nuevos impuestos destinados a incrementar la participación del Estado en la renta como el Impuesto al Patrimonio Rural (2013), la eliminación de la exoneración del Impuesto a la Enseñanza Primaria (2015) y del descuento del $18 \%$ en la Contribución Inmobiliaria Rural (desde 2016). Estas medidas elevaron en 2015 la presión sobre la renta tres puntos porcentuales y la presión fiscal casi dos puntos.

\section{CONCLUSIONES}

En el plano empírico esta investigación aporta tres hallazgos originales para el periodo bajo estudio: las series de distribución del ingreso por fuente de remuneración y de distribución social del ingreso para el sector agropecuario, y la primera serie sistemática de renta de la tierra agraria apropiada por el sector. A partir de su análisis conjunto es posible arribar a las siguientes conclusiones:

1) Este trabajo aporta a la reflexión reciente en la literatura académica en torno a la necesidad de estudiar las tendencias y los niveles de la distribución del ingreso en Uruguay, incorporando como novedad el abordaje de la renta del suelo como una fuente de plusvalor que no debería obviarse en los estudios de distribución dada su relevancia en una economía de base agropecuaria. Desde esta perspectiva, recuperar la crítica de la economía política como método de estudio puede iluminar aspectos de la realidad que suelen escapar de la comprensión de la teoría marginalista, como es el caso de las particularidades de la renta del suelo.

Los resultados muestran la relevancia cuantitativa (hasta $50 \%$ del valor agropecuario) y cualitativa de la renta agraria como forma del plusvalor en

Se eliminó el impuesto al patrimonio para el sector, se redujeron las tasas de la Contribución Inmobiliaria Rural, se exoneró el pago de aportes patronales y se bajaron las tasas del IMEBA. 
el valor agropecuario, en tanto el sector "exige" una masa extra de ganancias para remunerar a los terratenientes. Su magnitud absoluta y relativa in crescendo de 2003 a 2014, ligado a un contexto de altos precios de las mercancías agrarias y de flujo de IED hacia la tierra, reaviva una discusión típica de la economía política clásica, en tanto la existencia de renta es evidencia de las particularidades y limitaciones que imponen las ramas agrarias a la acumulación "normal" de capital, pues es necesario abonar una renta a los dueños del suelo. Asimismo, esta cuantía extra de plusvalor seguramente esté explicando el menor peso relativo del ingreso laboral en el producto agropecuario con respecto a las ramas industriales.

2) Las series de distribución del ingreso evidencian una tendencia persistente en los procesos económicos de las últimas décadas en América Latina: la dependencia del valor de la fuerza de trabajo con respecto al ciclo económico. Así, la crisis económica (2000-2003) se "resolvió" en el agro ajustando a la baja el valor de la fuerza de trabajo y la participación relativa del ingreso laboral, al tiempo que el periodo de crecimiento económico (2004-2013) permitió incrementar el valor de la fuerza de trabajo y la participación del ingreso laboral en el producto, pero no sin la mediación del Estado que operó activamente empujando al alza los salarios, en el contexto de un gobierno (el del Frente Amplio) que expresó la posibilidad coyuntural de un nuevo pacto de clases en Uruguay.

3) La evolución del ingreso real por clase permite evidenciar mejor la tendencia a la descomposición de la producción mercantil agraria, en tanto mientras el ingreso real de los asalariados crece un 76.1\%, el de la producción mercantil propietaria apenas crece $9.6 \%$, y para aquellos no propietarios cae un $16.1 \%$. Con estas tendencias no es difícil explicar porqué los productores de tipo familiar-mercantil se redujeron un $22 \%$ entre los años 2000 y 2011.

4) La actuación del Estado, aunque con nuevas mediaciones desde 2005, parece ajustarse en el periodo estudiado a los requerimientos de la acumulación de capital, en la medida que durante los ańos de crisis redujo la presión tributaria y permitió la desvalorización de la fuerza de trabajo, y durante el periodo de crecimiento elevó la presión tributaria y presionó al alza los salarios. De hecho, y a pesar de los constantes cuestionamientos que recibieron las modificaciones tributarias y la mayor regulación del conflicto capital-trabajo por parte de los representantes del capital agrario, no se está ante un incremento relativo significativo de la participación del Estado y del ingreso laboral en el producto agropecuario. 
En definitiva, los cambios registrados en el sector agropecuario en los últimos 15 ańos provocaron el incremento absoluto y relativo de los ingresos de capitalistas y terratenientes en un contexto caracterizado por un nuevo sistema tributario y por políticas de crecimiento del salario real. De allí que las iniciativas estatales orientadas a mejorar la distribución del valor lograron mantener la participación de los salarios y del Estado en el PIB, pero resultaron ineficaces a la hora de modificar el patrón de distribución. La encrucijada se abre con el inicio de una fase de retracción en los últimos dos años del análisis (2014-2015). La reducción registrada en la participación de las ganancias en el producto, que a igual stock de capital supone una reducción en la tasa de ganancia del capital agrario, ya produjo la retracción absoluta de la renta del suelo en 2015, y comienza a presionar para bajar la participación del ingreso laboral en el producto agropecuario. La disyuntiva para quienes conducen el Estado es si expresarán plenamente la necesidad de reducir impuestos y bajar salarios, o enfrentarán con una estrategia superadora las crisis recurrentes de la valorización del capital.

En este sentido, si el desafío es articular un proceso de acumulación de capital que no atente contra las condiciones de reproducción de la fuerza de trabajo, no parece haber más opción que avanzar sobre una fuente de plusvalor que no surge del propio proceso de producción sino del monopolio privado de la tierra: la renta del suelo. Sea con ajustes impositivos, sea regulando sus precios de transacción mercantil, o avanzando directamente sobre su propiedad, el Estado debería re-dirigir la renta del suelo hacia los sujetos que participan directamente de la producción y/o hacia sus propias arcas, en vez de permitir su apropiación por los dueños privados del suelo. 


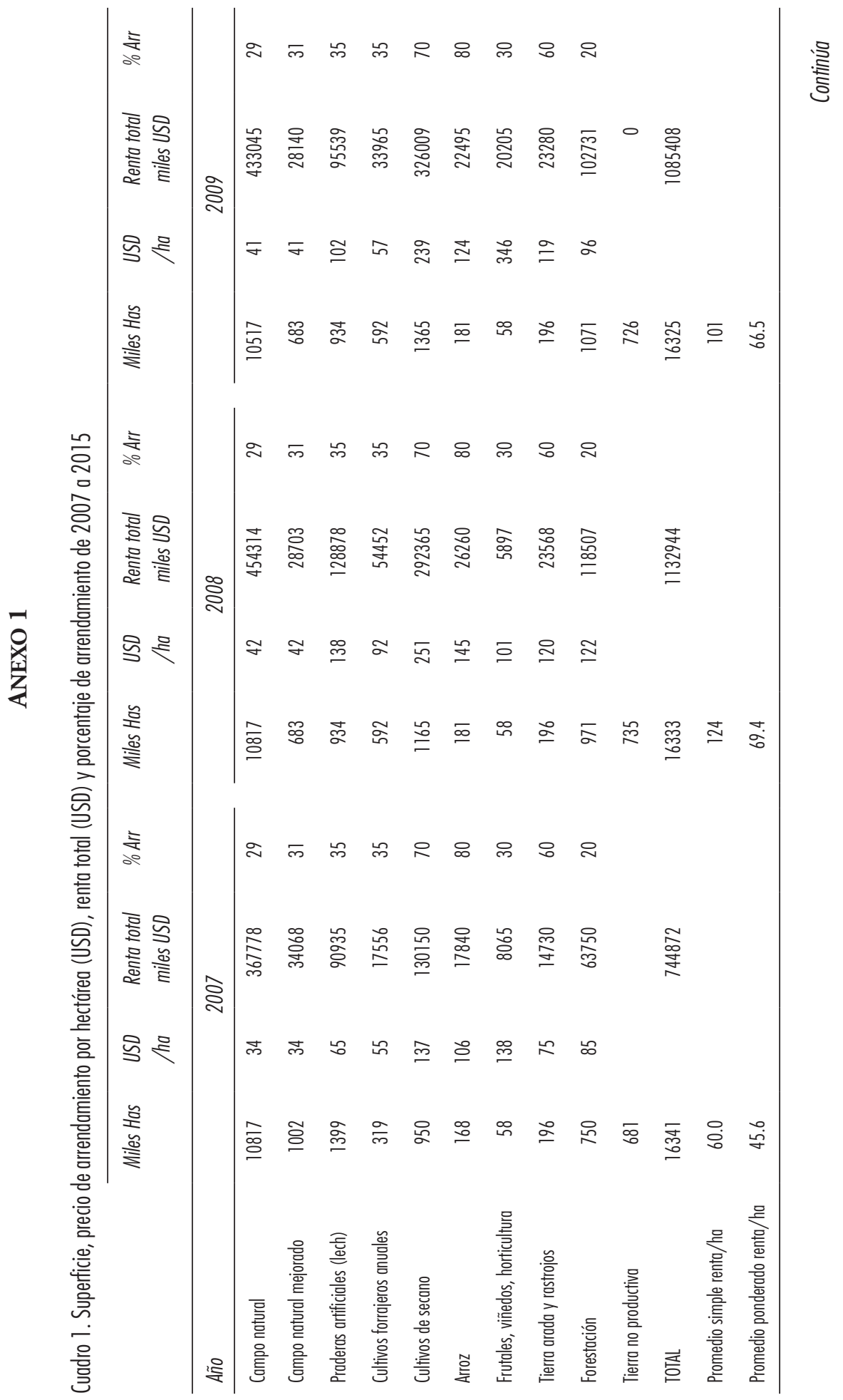




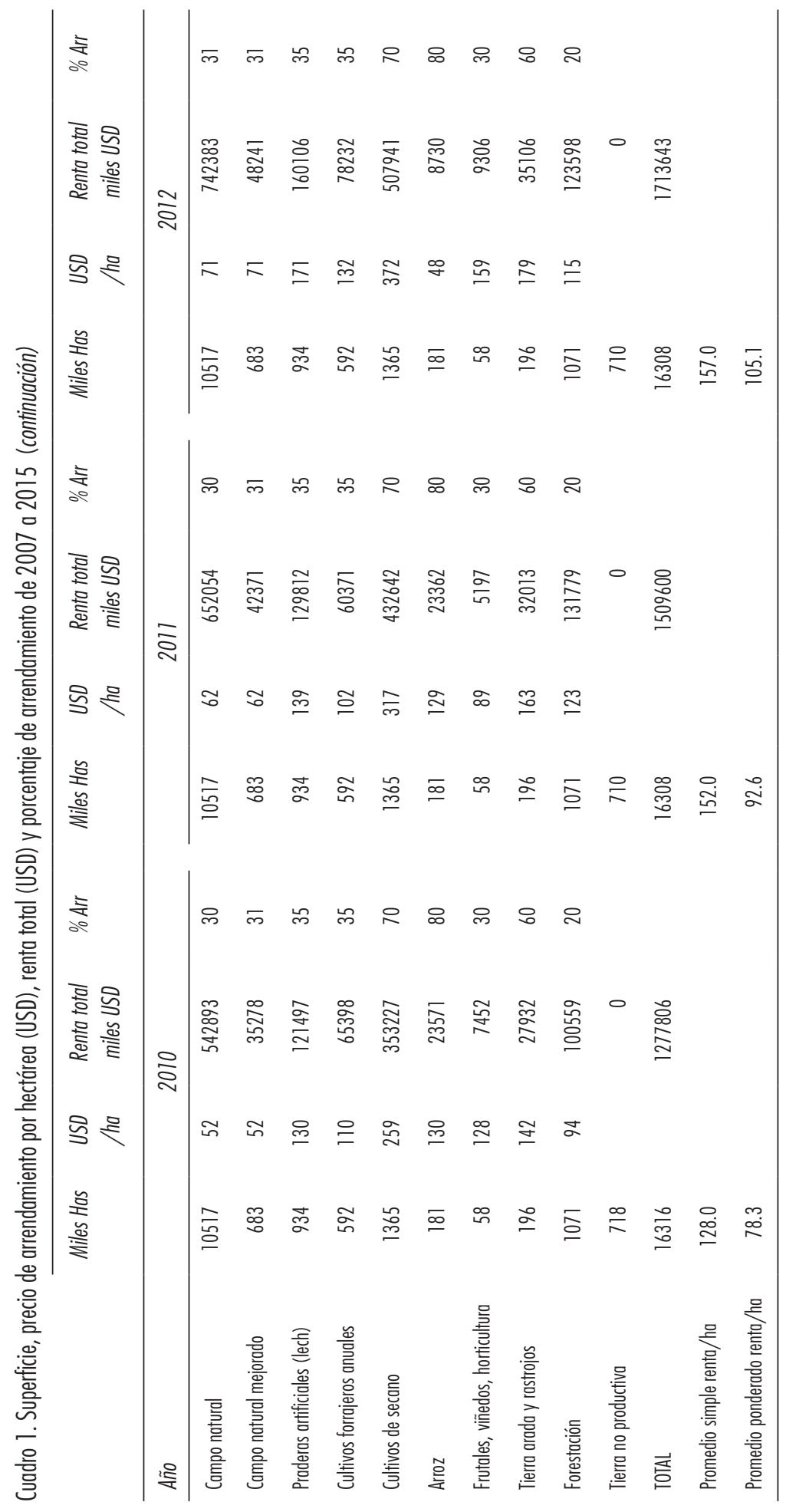




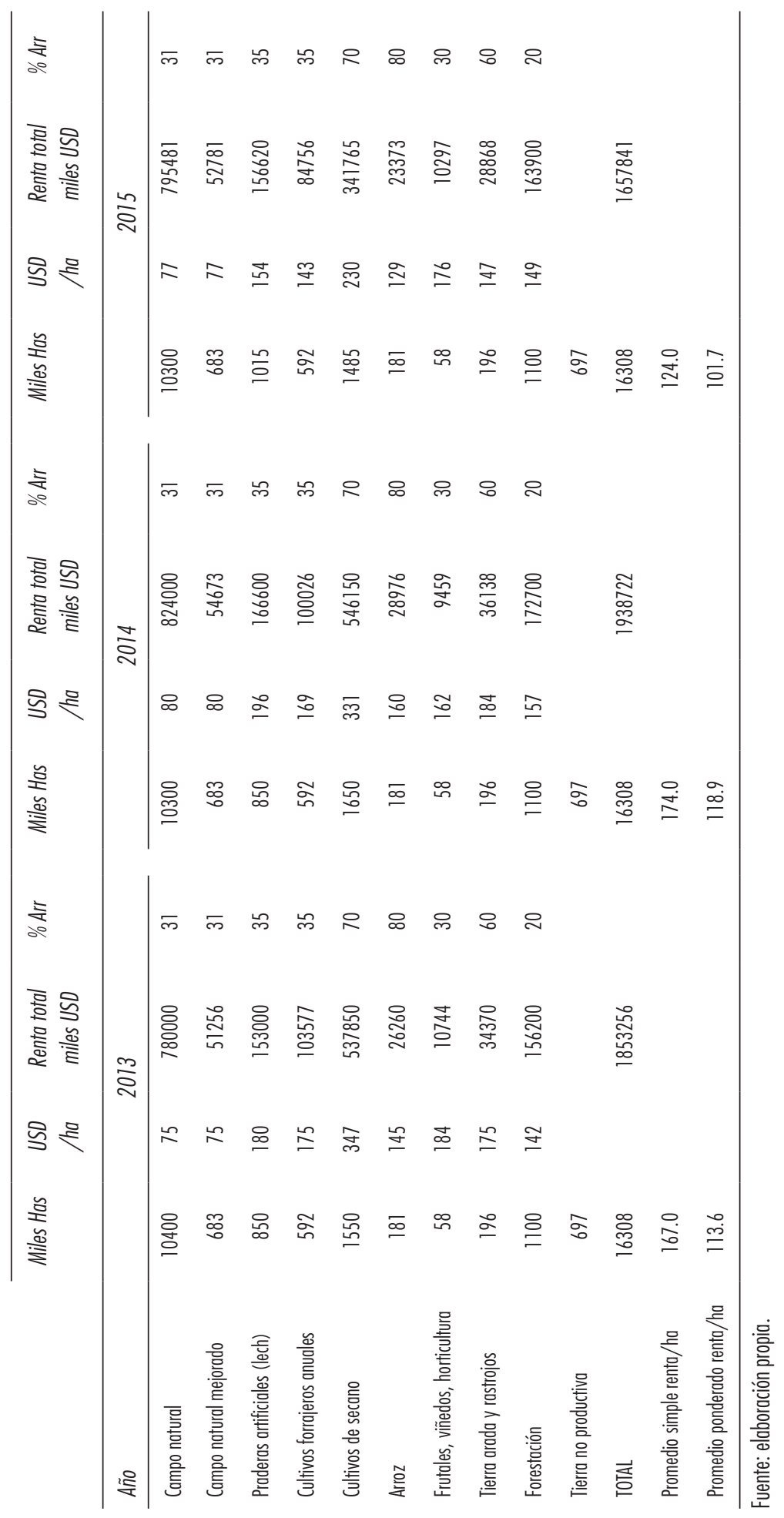




\section{ANEXO 2 \\ PROCESAMIENTO DATOS ECH Y BPS, AJUSTE TRABAJADORES 2010}

Los aportes personales se prorratearon en cada sector y tipo de trabajador (asalariado, ingreso mixto e ingreso patronal salarial) según la participación relativa de los trabajadores formales. Los aportes patronales se prorratearon según número de trabajadores por clase de actividad.

El procesamiento de la $\mathrm{ECH}$ consideró que hasta 2011 la CIIU era revisión 3 y cada actividad se define de la siguiente manera: Cría de animales y servicios ganaderos, ramas: 0121, 0122, 0123, 0129; Cultivos en general y servicios agrícolas, ramas: 0111, 0112, 0113; Silvicultura, rama: 0200. Los servicios agropecuarios en esta revisión, están todos juntos con el código 0140. Por lo que para los años 2011 hacia atrás se realizó un prorrateo que se detalla luego. Para la ECH 2012 y 2013, las actividades se define: Cría de animales y servicios ganaderos, ramas: de la 0141 a la 0150 y la 162; Cultivos en general y servicios agrícolas, ramas: de la 0111 a la 0130 y la 0161; Silvicultura, rama: 0210, 0220, 0230 y 0240. En la ECH 2012 se pueden identificar los servicios agropecuario en la rama que le pertenecen, lo anterior debido al cambio de revisión de la ciru. Por tanto, se utiliza el peso que tienen los trabajadores que brindan servicios en el total de los servicios. Con esa relación se realiza un sorteo con distribución Bernoulli, entre los trabajadores de cada rama 0140 (servicios agropecuarios) para cada actividad (ganadería, agricultura y silvicultura) con la probabilidad encontrada en el 2012. Este razonamiento se repite hasta encontrar el sorteo que halle la media de la distribución.

En el caso de los aportes patronales se estimó el dato agregado para todo el sector agropecuario publicado en BPS por rubro productivo. Para ello se utilizó la cantidad de hectáreas utilizadas por cada actividad, el índice CONEAT promedio de cada actividad para prorratear el dato administrativo del Bps. Finalmente, se prorrateó dentro de cada actividad entre la cantidad de asalariados, cuenta propia y patrones. En el caso de los aportes personales a la seguridad social y al seguro de salud (FONASA) se prorratearon los datos administrativos del BPs entre los distintos tipos de trabajadores y las ramas de actividad según la cantidad relativa de trabajadores formales. Para el FONASA no hay publicados datos de recaudación por sector de actividad, por lo tanto, se estableció una tasa de 3\% si gana menos de 3 врс (tomando el nominal construido con los aportes personales) sobre los formales. Si supera los 3 в РС se aplica $4.5 \%$ más un 1.5 adicional si tiene hijos a cargo. 
En el año 2010, la ECH sobrestima la población del sector en general y la cantidad de asalariados en particular, algo que no ocurre para las remuneraciones promedio de asalariados, ingreso mixto y salarios patronales. Por ese motivo, se ajustó el total de personas para ese año por el valor promedio del total de personas en cada una de las ramas en el periodo analizado, excluyendo de la construcción del promedio el ańo 2010.

\section{ANEXO 3}

\section{INGRESOS DEL ESTADO}

Los tributos que afectan a los propietarios de la tierra son la Contribución Inmobiliaria Rural (1.25\% del valor catastral de la tierra, que es siete veces más bajo que el precio de mercado), el Impuesto al Patrimonio Rural (abonan unos 1400 propietarios que pagan una tasa de entre 0.7 y 3\%) y el Impuesto de Enseñanza Primaria. Los tributos que gravan la producción son los impuestos a las ganancias, los impuestos indirectos y las detracciones. Los impuestos que afectan las ganancias son el Impuesto a la Enajenación de Bienes Agropecuarios (IMEвA) que grava la producción enajenada con un porcentaje que varía según el rubro entre 0.1 y $2 \%$; el Impuesto a la Renta de las Actividades Empresariales (IRAE) que grava con una tasa de $25 \%$ las ganancias y los aportes patronales al врs. Los impuestos indirectos son el IVA costos y la Tasa de Registro. E impuestos a la exportación que por la Ley 17.780 de mayo de 2004 sólo se cobran con una tasa de $5 \%$ a los cueros sin procesar.

En el caso de la recaudación del INC, como sólo se obtuvieron los balances del periodo 2010-2015, se estimó la recaudación de 2000 a 2009 considerando que en el periodo para el que se cuenta información el INC subsidió en un $57.7 \%$ el valor de las rentas, comparando lo efectivamente recaudado con el potencial recaudatorio si todas las tierras bajo su propiedad obtuvieran la renta de mercado ponderada. 


\section{BIBLIOGRAFÍA}

Abeles, Martín, Verónica Amarante y Daniel Vega (2014), "Participación del ingreso laboral en el ingreso total en América Latina, 1990-2010", Revista Cepal, núm. 114, Santiago de Chile, Cepal, diciembre, pp. 31-52.

Alarco, Germán (2014), "Participación salarial y crecimiento económico en América Latina, 1950-2011”, Revista Cepal, núm. 113, Santiago de Chile, Cepal, agosto, pp. 43-60.

Banco Central del Uruguay (вС)) (2016), "Sistema de Cuentas Nacionales" (consultado el 15 de junio de 2016), disponible en http://www.bcu.gub. uy/Estadisticas-e-Indicadores/Paginas/Default.aspx

Burdín, Gabriel, Fernando Esponda y Andrea Vigorito (2014), Desigualdad y sectores de altos ingresos en Uruguay: un análisis en base a registros tributarios $y$ encuestas de hogares para el periodo 2009-2011, Serie Documentos de Trabajo DT 06/2014, Montevideo, Instituto de Economía, pp. 50.

, Mauricio De Rosa y Andrea Vigorito (2015), Sectores de altos ingresos en Uruguay: participación relativa y patrones de movilidad en el periodo 2009-2012; Serie Documentos de Trabajo DT 03/2015, Montevideo, Instituto de Economía, pp. 53.

Carámbula, Matías, Joaquín Cardeillac, Bolívar Moreira, Agustina, Gallo et al (2012), "Los límites de la ciudadanía: el caso de los trabajadores asalariados rurales", en Alberto Riella (coord.), El Uruguay desde la sociología X, Montevideo, Facultad de Ciencias Sociales, pp. 351-370.

Comisión Económica para América Latina y el Caribe (Cepal) (2015), La Inversión Extranjera Directa en América Latina y el Caribe, Santiago de Chile, Cepal, pp. 144.

De Rosa, Mauricio y Andrea Vigorito (2015), Los vínculos entre la distribución personal y funcional del ingreso: Una exploración para Uruguay en base a registros tributarios, Montevideo, Instituto de Economía-Centro de Estudios Fiscales-AECID, pp. 40.

Dirección de Estadística Agropecuaria (DIEA) (2003), Censo General Agropecuario 2000, Resultados definitivos, Tomo II, Montevideo, DIEA-Mgap, pp. 43.

(2014), Censo General Agropecuario 2011. Resultados definitivos, Montevideo, DIEA-MGAP, pp. 142.

(2015), Anuario estadístico 2015, Montevideo, DIEA-Mgap, pp. 215. (2016a), "Serie 'precio de la tierra', Compraventas Año 2015" (consultado el 15 de marzo de 2016), disponible en http://www.mgap.gub.uy/ portal/page.aspx?2,diea,diea-principal,O,es,0, 
(2016b), "Serie 'precio de la tierra', Arrendamientos Año 2015” (consultado el 10 de junio de 2016), disponible en <http://www.mgap.gub.uy/ portal/page.aspx?2, diea,diea-principal, $\mathrm{O}$,es, 0 ,>

Dirección General Impositiva (DGI) (2016), "Datos y series estadísticas" (consultado el 20 de junio de 2016), disponible en <http://www.dgi.gub.uy/ wdgi/page?2,principal,dgi--series-de-datos, $\mathrm{O}$,es, 0 ,>

Foladori, Guillermo (2013), Renta de la tierra y acumulación de capital, 2a edición ampliada y actualizada, Montevideo, Trabajo y Capital, pp. 251.

Instituto Cuesta Duarte (2011), "La Masa Salarial entre 1998 y 2010" (consultado el 23 de junio de 2016), disponible en <http://www.cuestaduarte. org.uy/>

Instituto Nacional de Estadística (INE) (2016), "Industria, Comercio y Servicios" (consultado el 26 de junio de 2016), disponible en <http://www.ine. gub.uy/web/guest/industria-comercio-y-servicios>

Iñigo Carrera, Juan (2007), La formación económica de la sociedad Argentina. 1882-2004, Buenos Aires, Imago Mundi, pp. 299.

Marx, Karl (1980) [1895], El capital, Tomo III, Libro tercero, El proceso global de la producción capitalista [ed. Friedrich Engels], México, Siglo XXI Editores, pp. 1314.

Notaro, Jorge (2012), "La distribución social del ingreso: Marco teórico e indicadores", REBELA, vol. 1, núm. 3, Brasil, IELA, febrero, pp. 337-355.

Olmos, Leticia (2015), Estructura del Valor Agregado Sectorial: estimación a partir de registros tributarios, Montevideo, Centro de Estudios Fiscales, pp. 8.

Programa de las Naciones Unidas para el Desarrollo (pNud) (2008), Desarrollo humano en Uruguay 2008: Política, politicas y desarrollo humano, Montevideo, PNud-Uruguay, pp. 389.

Tambler, Adrián (2000, 2005, 2009, 2015), "Presión fiscal en el agro", en OPYPA (org.) Anuarios OPYPA (2000-2005-2009-2015), Montevideo, MGAP-OPYPA.

Tommasino, Humberto, Ángela Cortelezzi, Mario Mondelli, José Berbejillo y María Eugenia Silva Carrazzona (2014), "Tipología de productores agropecuarios: caracterización a partir del Censo Agropecuario 2011”, en OPYPA (org.), Anuario OPYPA 2014, Montevideo, MGAP-OPYPA, pp. 18.

Uruguay XXI (2015), "Informe anual comercio exterior" (consultado el 20 de junio de 2016), disponible en <http://www.uruguayxxi.gub.uy/> 
